\title{
Implementing Strategies for Strengthening Australia's Rural Allied Health Workforce
}

\author{
Catherine Cosgrave \\ University of New England, ccosgra2@une.edu.au
}

Follow this and additional works at: https://nsuworks.nova.edu/ijahsp

Part of the Civic and Community Engagement Commons, Community-Based Research Commons, Health and Medical Administration Commons, Medicine and Health Commons, Other Medicine and Health Sciences Commons, and the Rural Sociology Commons

\section{Recommended Citation}

Cosgrave C. Implementing Strategies for Strengthening Australia's Rural Allied Health Workforce. The Internet Journal of Allied Health Sciences and Practice. 2021 Oct 01;19(4), Article 8.

This Manuscript is brought to you for free and open access by the College of Health Care Sciences at NSUWorks. It has been accepted for inclusion in Internet Journal of Allied Health Sciences and Practice by an authorized editor of NSUWorks. For more information, please contact nsuworks@nova.edu. 


\title{
Implementing Strategies for Strengthening Australia's Rural Allied Health Workforce
}

\begin{abstract}
Purpose: In many rural places, health services struggle to maintain an adequate health workforce to meet their communities' health care needs. Shortages of allied health professionals are of particular and growing concern. To address this challenge, a two-year Whole-of-Person Retention Improvement Project was developed involving a research partnership with two rural public health services in Victoria, Australia. This project was informed by the author's Whole-of-Person Retention Improvement Framework (WoP-RIF), aimed to produce new knowledge for rural health services to attract, recruit, and improve the retention of allied health professionals. A set of evidence-informed and contextually relevant recommendations were made in the project's initial observational phase to strengthen each service's allied health workforce, 10 of which were shared. The objective of this phase of the project was to explore the challenges and enablers that two rural health services experienced in developing and implementing strategies for allied health workforce improvement. Method: The methodological approaches used for this intervention study were participatory action research and a realist evaluation. The data sources used for the realist evaluation included qualitative (focus group) and observational (project documents and fieldnotes). Results: The results outline the key responses made by the regional and rural health service to implement the 10 shared recommendations and are presented under their relevant WoP-RIF domains: workplace/organisational, role/career, and community/place. The key and shared contexts, drivers, mechanisms, outputs, and outcomes are presented under each recommendation, and where possible, an assessment is made regarding sustainability beyond the project period. Conclusions: The implementation of the recommendations is a complex process requiring whole-of-organisation support by the participating rural public health services. This study identifies five facilitators for successful implementation: 1) the project is considered a strategic human resources initiative and overseen by the executive; 2) it has strong champion(s) in the executive staff; 3) human resources is part of the strategic decision-making arrangements; 4) the change management process is facilitated and led by staff from the target clinical workforce(s); and 5) a partnership approach with local council is adopted for strategies requiring community support and engagement.
\end{abstract}

\section{Author Bio(s)}

Dr Catherine (Cath) Cosgrave PhD, MA, B.Com, Churchill Fellow 2018 is an adjunct Research Fellow at New England Institute of Healthcare Research, School of Rural Medicine, University of New England. Dr Cosgrave is a social scientist and qualitative researcher with internationally recognised expertise in rural health workforce.

\section{Acknowledgements}

Acknowledgements: Dr Cosgrave acknowledges the executive staff, allied health managers, and newly recruited allied health professionals who generously gave their time to participate in this study, and also the support of University of Melbourne - Department of Rural Health and the two Victorian public health services that participated. This project was funded under the Australian Government Department of Health Rural Health Multidisciplinary Training Program. The views expressed in this publication are those of the author and do not necessarily reflect the views of the funding agency. Dr Cosgrave wishes to thank $\mathrm{Dr}$ Christina Malatzky for providing feedback on early drafts of this manuscript, Joanna Dolan for editing, and Bruce Naylor for graphic design. 


\title{
IIIAHSP \\ The Internet Journal of Allied Health Sciences and Practice \\ Dedicated to allied health professional practice and education \\ Vol. 19 No. 4 ISSN 1540-580X
}

\section{Implementing Strategies for Strengthening Australia's Rural Allied Health Workforce}

\author{
Catherine Cosgrave
}

University of New England

Australia

\begin{abstract}
Purpose: In many rural places, health services struggle to maintain an adequate health workforce to meet their communities' health care needs. Shortages of allied health professionals are of particular and growing concern. To address this challenge, a two-year Whole-of-Person Retention Improvement Project was developed involving a research partnership with two rural public health services in Victoria, Australia. This project was informed by the author's Whole-of-Person Retention Improvement Framework (WoP-RIF), aimed to produce new knowledge for rural health services to attract, recruit, and improve the retention of allied health professionals. A set of evidence-informed and contextually relevant recommendations were made in the project's initial observational phase to strengthen each service's allied health workforce, 10 of which were shared. The objective of this phase of the project was to explore the challenges and enablers that two rural health services experienced in developing and implementing strategies for allied health workforce improvement. Method: The methodological approaches used for this intervention study were participatory action research and a realist evaluation. The data sources used for the realist evaluation included qualitative (focus group) and observational (project documents and fieldnotes). Results: The results outline the key responses made by the regional and rural health service to implement the 10 shared recommendations and are presented under their relevant WoP-RIF domains: workplace/organisational, role/career, and community/place. The key and shared contexts, drivers, mechanisms, outputs, and outcomes are presented under each recommendation, and where possible, an assessment is made regarding sustainability beyond the project period. Conclusions: The implementation of the recommendations is a complex process requiring whole-of-organisation support by the participating rural public health services. This study identifies five facilitators for successful implementation: 1) the project is considered a strategic human resources initiative and overseen by the executive; 2) it has strong champion(s) in the executive staff; 3) human resources is part of the strategic decision-making arrangements; 4) the change management process is facilitated and led by staff from the target clinical workforce(s); and 5) a partnership approach with local council is adopted for strategies requiring community support and engagement.
\end{abstract}

Keywords: rural health workforce; allied health; local context; recruitment; retention; turnover; Australia 


\section{INTRODUCTION}

Globally, the health workforce is maldistributed. There are higher concentrations of health professionals living in urban as opposed to rural settings, and numbers of "in-place" health professionals decrease with increasing remoteness. ${ }^{1}$ In many rural places, health services struggle to attract and maintain an adequate health workforce to meet the health care needs of their communities. ${ }^{2}$ Rural shortages of allied health professionals (AHPs) in Australia is a long standing issue and gaining increasing attention from the government in the last few years. $3,4,5$

This research is the second phase of a larger project titled the Whole-of-Person Retention Improvement Project (WoP-RIP) that aimed to produce new knowledge regarding how rural-based public health services can better attract, recruit and improve the retention of AHPs. ${ }^{6}$ Underpinning this project is the Whole-of-Person Retention Improvement Framework (WoP-RIF). ${ }^{7}$ While the title of the WoP-RIP and its underpinning framework emphasise retention, improved retention is reliant on attracting high quality candidates and prioritising 'person-environment-fit' for staff recruitment.

The framework was created specifically to support rural health services' executives and line managers, rural communities, and governing bodies to develop evidence and place-informed, whole-of-community, strategic actions to improve rural health workforce retention. It incorporates human resources management, place and belonging and community engagement (including workforce literacy) concepts, all of which are relevant to addressing rural health workforce challenges.8,9,10,11 The WoP-RIF includes three domains: workplace/organisational, role/career and community/place to explain the full-range of factors identified in the extant literature as influencing rural health professionals' decision-making regarding attraction, recruitment and retention and sets out pre-conditions for improving retention under each domain (see Figure 1).

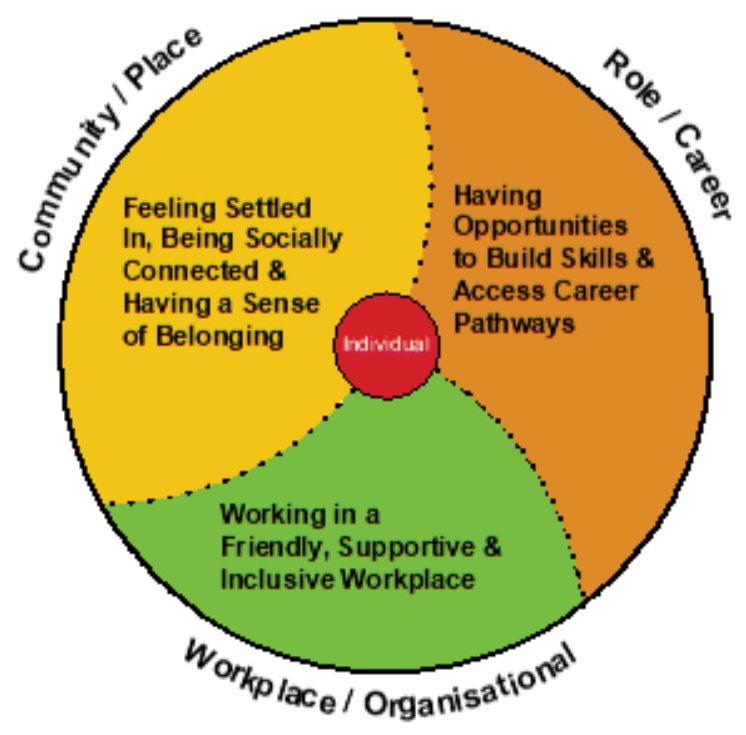

Figure 1. The "Whole of Person" Retention Improvement Framework

The WoP-RIP was undertaken in two rural-based public health services in and funded by the State of Victoria, including a regional health service (ReHS) and a medium-sized rural health service (RuHS). The project uses Allied Health Professions Australia's definition of AHPs as qualified health practitioners with specialist skills in preventing, diagnosing, and treating a range of conditions and illnesses. In Victoria's public health services, AHPs are categorised into two groups: the therapies and the sciences. In the RuHS, the AH workforce was relatively small (approximately 25 full-time equivalent staff (FTE)) and almost all worked in a single community health team in a single location. In the ReHS, the AH workforce was around 115 FTE working across several teams/services in various buildings and sites. The decision to select two differently sized health services was made to support a rich exploration of $\mathrm{AH}$ staffing challenges in rural contexts.

The project ran over a two-year period (January 2018 to December 2019). A legal project partnership agreement was made between University of Melbourne, Department of Rural Health (UoM-DRH) and each service. All stakeholders contributed financial resourcing to cover the appointment of a project worker at each service. Project governance arrangements for each service included the operation of a Project Reference Group (PRG) and a Project Working Group (PWG). The ReHS' PRG comprised mainly senior AH managers, some of whom were members of the executive, as well the head of HR (also a member of the executive), a community representative (discussed in results at 10) and the UoM-DRH director. The RuHS' PRG involved the 
executive, including the CEO, the community services director and the UoM-DRH director. The PWG members at each service included the author, an assigned senior AH manager and the appointed project worker. In both services, the appointed project worker was an AHP with substantive experience working in public health who had previously relocated to the town/region.

The first phase of the WoP-RIP was a six-month (January-June 2018) observational study to identify the contextual factors impacting the recruitment and retention of AHPs. A qualitative approach applying a constructivist-interpretivist methodology was used and resulted in a set of evidence-informed and contextually specific recommendations for each service to help strengthen their AH workforces. ${ }^{6}$ Fourteen recommendations were made for the ReHS and 13 for the RuHS. Ten of these recommendations were common to both services. This paper focuses on the second phase of the research project, an intervention study that took place over an 18-month period (June 2018-December 2019) and evaluates the strategies developed and implemented by both services to address these 10 shared recommendations.

\section{METHODS}

\section{Aims}

The objective was to explore the challenges and enablers that two rural health services experienced in developing and implementing strategies for $\mathrm{AH}$ workforce improvement. The research questions underpinning the intervention study were:

- To what extent were the services able to implement the recommendations aimed at improving the attraction, recruitment, and retention of their $\mathrm{AH}$ workforces?

- To what extent were the outputs/outcomes achieved considered sustainable beyond the life of the WoP-RIP?

- What are the critical factors rural health services need to consider when developing their own AH workforce strategy?

Ethical approval for the study was granted by the UoM-DRH's Human Ethics Advisory Group (1749205).

\section{Research Design}

The methodological approaches used for this intervention study were participatory action research (PAR) and a realist evaluation. PAR was selected for its appropriateness in projects concerned with adaptation and transition, where the goal is to engage and empower communities to respond to issues that affect them in place-specific ways. PAR is a co-learning process between a researcher(s) and community members that emphasises collaborative inquiry and adaptive action. ${ }^{12}$ Its purpose is to gather research findings that are context-informed and can be translated into actions to support local change as well as strengthen local knowledge. ${ }^{12}$ The process involves iterative cycles of collective learning (reflect>plan>act>observe) that lead to further inquiry and/or new actions for change. $10 \mathrm{~A}$ realist approach to evaluation involves the collection of context-sensitive project and process data to help build understanding about what works best, for whom, in what circumstances, and why?. ${ }^{13}$ In realist evaluation, mixed methods data collection is commonly used, including the gathering of qualitative, quantitative and observation data. ${ }^{14}$ Analysis of this data involves identifying causal forces behind identified patterns or changes in patterns that are the "context-mechanismoutcome configuration." 14 It also involves the development of "initial program theories" based on inductive and deductive reasoning and researcher insights into hypothesising how, why, and for whom the intervention is working. ${ }^{14}$

In this intervention study, the PWG members had different roles: the assigned senior AH manager and project worker (the servicebased PWG members) were solely responsible for the organisation's implementation of the recommendations. This involved the plan and act components of the action research cycle. While all PWG members participated in the observe and reflect parts of the action research cycle these were primarily led by the author, who undertook the realist evaluation. During PWG meetings, the author presented her iterative data analysis from this evaluation. The PWG reported quarterly to the PRG on key evaluation findings and progress-to-date on the implementation of recommendations.

\section{Data Sources and Data Collection}

The realist evaluation was carried out in three stages: consultation, concurrent, cross-sectional (see Figure 2). The concurrent evaluation methodology was employed to gather and analyse data (observe and reflect) and then feed back to the PWGs throughout the intervention period. This enabled PWGs to reflect on the evaluation questions and use periodic evaluation data to then iteratively change or improve (reflect>plan>act) the strategies being implemented to address the recommendations. The cross-sectional evaluation methodology focussed on gathering data from the target staff and key informants in each site in the last quarter of the project. 


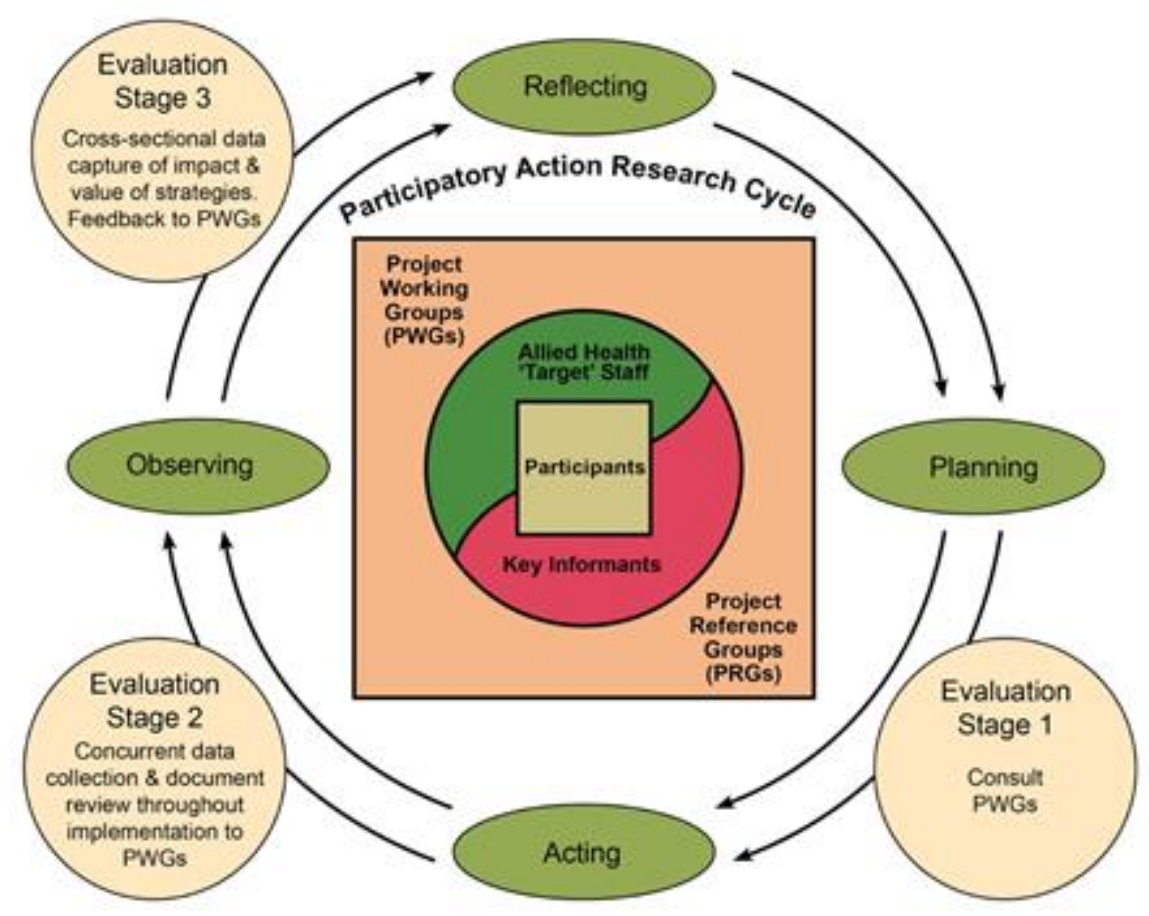

Figure 2. Evaluation Methodology

The data sources used for the realist evaluation included qualitative (focus groups) and observational (project documents and fieldnotes). The focus groups involved the participants from the earlier observation study. When recruiting for the focus groups, the author made email contact with participants to invite them to take part in a focus group at a particular date and time and, as a reminder, resent the plain language statement and consent form. Target focus group participants included: the AH 'target' staff group (AHPs in "early career" [defined as working three years or less as an AHP] and "experienced" AHPs who had relocated to the town within the previous 12 months) and key informants (primarily AH managers and members of the executive). Five focus groups were conducted in each service: three AH target staff focus groups (two in 2018 and one in 2019) and two key informant focus groups (one in 2018 and one in 2019). The focus groups undertaken in 2018 were part of the concurrent data collection (stage 2). Their purpose was to assess participants' awareness level of WoP-RIP strategies and/or activities (and, if aware, to collect feedback) and encourage suggestions on effective ways to implement the recommendations. The 2019 focus groups were part of the cross-sectional data collection (stage 3). All focus groups were audio-recorded, externally transcribed verbatim into separate Word documents and checked for accuracy against the original recording.

Documents and field notes used for the concurrent and cross-sectional data stages of the evaluation included: monthly implementation activity reports written by the project worker for the author and the author's field notes from the PWG and PRG meetings and focus groups and key evaluation findings written in the annual project reports written by members of the PWG for the PRG and tabled papers and minutes from the PRG meetings.

\section{Data Analysis and Rigour}

The data was thematically analysed using a constant comparative method to identify contexts, drivers, mechanisms (barriers and facilitators), outputs, and outcomes in regard to the implementation of the $\mathrm{AH}$ workforce improvement recommendations. ${ }^{15,16}$ These were circulated to the PWG and, if indicated, plans for recommendations were revised. For the writing of the final project reports and this paper, the author undertook a thematic analysis to locate common patterns across the identified drivers, mechanisms (barriers and facilitators), outputs, and outcomes and determine the critical factors for implementing an AH workforce improvement strategy in rural settings. ${ }^{17}$ The author used NVivo v12 software (QSR International) to support this analysis. To check the rigour of the author's analysis, during PWG and PRG meetings other members were routinely asked whether the data analysis and the themes identified were relatable. To safeguard participant confidentiality, the focus group transcripts were not shared with the other PWG members. The author only presented the findings thematically. 


\section{RESULTS}

The key responses made by the ReHs and RuHS to implement the 10 shared recommendations aimed at improving AH attraction, recruitment, and retention are presented under their relevant WoP-RIF domains: workplace/organisational, role/career and community/place. The key and shared contexts, drivers, mechanisms, outputs, and outcomes are presented under each recommendation and, where possible, an assessment is made regarding sustainability beyond the project period.

\section{Organisational}

1. Ensure new staff needing to relocate for work are routinely offered paid transitional accommodation and reimbursement of relocation costs.

The RuHS routinely offered accommodation and financial support to all new clinical staff needing to relocate to offset the costs of relocation, while the ReHS did not generally offer any relocation support to its AH staff. The recruitment incentives offered by the RuHS (a minimum of eight weeks' paid transitional accommodation and up to $\$ 1,000$ reimbursement of relocation costs) were intended to make the service's clinical positions more broadly attractive to candidates and help address the well-known challenges of finding suitable rental accommodation in the town. In the intervention phase of WoP-RIP, the RuHS' executive approved an increase in the recruitment incentive to a minimum of 12 weeks' paid transitional accommodation, as well as maintaining the $\$ 1,000$ reimbursement for relocation costs incurred. In the ReHS, the need to provide transitional accommodation assistance to help attract quality medical staff was already in place. Over the life of the WoP-RIP, the executive increasingly understood and accepted, based on the evidence presented to them, the need to extend transitional accommodation support to the AH workforce. This shift in attitude was due, in part, to the effectiveness of a recruitment incentive trial targeting a difficult-to-recruit AH discipline. The trial offered successful candidates needing to relocate four weeks' accommodation support. By the end of the project, the executive had commissioned a review to develop an organisation-wide clinical recruitment incentive policy.

\section{Identify the main attractors/detractors impacting the successful recruitment and retention of AH staff and develop marketing materials that promote the benefits and opportunities for use in recruiting.}

To attract AHPs who are the 'right person' for the work and place context, the author recommended that both services include a standard interview question to help determine candidates' 'fit' for the service and the place/town. The proposed interview question developed by members of both PWGs was: What opportunities and challenges do you think you will experience in the first 12 months of living and working in X [town's name]? And what strategies will you use to address these identified challenges? In the ReHS, the HR department agreed to include this as a compulsory question in the organisation's interview templates for clinical and non-clinical staff. In the RuHs, the HR department was resistant to making any changes to the policy and procedures concerning recruitment of clinical staff. So, while this interview question was being used by some $\mathrm{AH}$ managers during the project period, the PWG considered it unlikely that it will be sustained unless it is formally adopted as one of the organisation's standard interview questions.

The component of the recommendation relating to development of marketing materials was addressed in both services by developing a marketing strategy. For the ReHS, this strategy was part of a decision by the executive to create an organisationwide clinical workforce development plan. Conversely, the RuHS strategy was AH-specific and developed from a SWOT analysis of AH workforce undertaken by the project worker and HR department. In both services, the WoP-RIF was used to guide the development of these marketing strategies. This involved consideration of the service's and town's strengths and opportunities and, in particular, identifying positive points of difference from other services and rural towns.

In the ReHS, the marketing strategy outputs primarily focused on development of YouTube videos involving interviews with existing staff. The first video produced covered the whole clinical workforce (medical, nursing and AH) while later videos focused on specific health workforces. All video resources are available publicly through the service's website and its recruitment portal. The RuHS' marketing strategy targeted AH professionals with experience living/working rurally (including students who had undertaken rural clinical placements) and those attracted to a rural lifestyle. The strategy focused on promoting the service's extended role and career opportunities, including above-award professional development support and a commitment to the provision of high-quality clinical supervision. With regard to entry-level AH professionals, Victorian regional universities were targeted, and promotion efforts were focused on final year AH students. The medium-term marketing strategy plans are to expand the RuHS advertising of $\mathrm{AH}$ positions to the relevant $\mathrm{AH}$ professional association as well as continuing advertising in SEEK, the services' website, and in local newspapers. In the medium-term, the aim is to increase use of social media to strengthen the service's organisational profile and advertise vacancies more broadly. This includes developing a range of organisational videos for YouTube (e.g. a virtual tour of the service; interviews with current staff on their reasons for working at the service) as well as posting job advertisements and organisational achievements on Facebook and Linkedln.

(C) The Internet Journal of Allied Health Sciences and Practice, 2021 
Both services already supported a grow-your-own clinical workforce strategy and focused on promoting health careers to local high school students and participating in the local annual career-day events, as well as school-based vocational education and work experience programs. In the ReHS, as part of this project, the AH resource materials distributed to high school students were updated to better reflect the identified factors influencing the attraction, recruitment, and retention of entry-level AH staff. As part of its marketing strategy, the RuHS is planning to strengthen its grow-your-own approach by implementing a process to identify and make connection with 'local' AH students and professionals either currently living in the town/region or studying/working elsewhere. Proposed activities to encourage this "local" cohort to consider working at the service include offering AH assistant positions to $\mathrm{AH}$ students during university semester breaks; and, through email, providing regular service updates including new programs and facilities, and promoting vacant positions.

\title{
3. Streamline HR systems and recruiting processes to support faster recruitment/onboarding of new AH staff.
}

Staff and managers in both services commonly experienced their HR recruitment processes as being heavily compliance-focused and overly complex, resulting in unnecessary delays in the recruitment of $\mathrm{AH}$ staff. $\mathrm{AH}$ managers attributed these delays in the RuHS to reliance on a manual system (except for credentialling and police checks). While there is a planned move to a full electronic system by the executive, implementation has been delayed for several years due to budgetary constraints and low prioritisation.

Conversely, the ReHS was already operating a fully electronic system and its delays were attributed to a cumbersome approval process. This included needing approval from a large number of persons before being able to advertise a permanent position, and not being able to notify the 'preferred' candidate until referee and police checks were completed. In the first year of the intervention component of WoP-RIP, AH managers observed improvements in the recruitment process - fewer signatures were required before advertising a position, and a preferred candidate could be offered a position immediately after interview, subject to their passing the necessary checks. However, AH turnover was discussed by ReHS senior AH managers as continuing to be high because many AH staff were on short-term contracts and/or part-time/fractional appointments. These staff often left the service to take up more secure employment. In response, the service-based PWG members developed the Optimal Recruitment Policy (ORP). The ORP outlines the criteria and process for converting AH staff on fixed term contracts (including locums) to permanent positions. The policy includes a template for AH managers to complete and present, including the supporting business case and data required, to the executive for consideration and approval. In the ReHS' final report for this project, the service-based PWG members described this recommendation as being one of the most challenging to make progress on but had the potential to be "the most impactful project outcome."

\begin{abstract}
Workplace
4. Ensure AH managers have an evidence-based understanding of the factors influencing recruitment and retention of AHPs in rural health services and, in particular, the importance of their being skilful leaders and supportive managers. AH managers in both services were seen as often having low levels of leadership skills. The PWG attributed this to rurally-based $\mathrm{AH}$ managers commonly being promoted relatively early in their careers (compared to metro-based) and that university training did not adequately prepare AHPs for management roles. Research evidence emphasises the importance of skilled AH clinical leadership and identifies staff retention as being strongly impacted by the quality of workplace relationships, especially the relationship workers have with their line manager/supervisor. 7,8 In rural health services, the line manager is also commonly viewed by staff as representing the "organisation" and thus the level and quality of support they give to their staff is equated with the organisation's level of commitment. ${ }^{8}$ Both services undertook activities to help build PRG and other AH managers' understanding of the evidence-base on what influences AH staff job/personal satisfaction. This involved both project workers regularly presenting the WoP-RIF and the research evidence underpinning the framework to the executive, AH managers and clinical staff throughout the project. Towards this project's end, the ReHS executive, as part of developing the organisation's clinical workforce implementation plan, decided to adopt the WoP-RIF across the whole organisation.

In addition, in the second year of the intervention component, the ReHS PWG organised two training days for AH managers. These training days, run by external providers, focused on building leadership skills and targeted AH staff new to supervisory roles (moving from Grade 1 to Grade 2 under the Victorian Enterprise Bargaining Agreement) and more experienced AH managers respectively. Both sessions were well attended $(n=32$ and $n=21)$. Based on evaluation surveys distributed by the project worker to attendees, almost all participants were 'very satisfied' with the training. At the end of the WoP-RIP, the PRG and the HR department were investigating ways to fund and deliver annual AH leadership training workshops. The ReHS' AH Clinical Education Coordinator also established a monthly support program targeting AH staff who were new to supervisory roles. The program was developed to encourage peer support and leadership skills. Content included: expected capabilities and challenges for staff new to Grade 2, managing difficult conversations, personality type and communication style, and providing clinical supervision.
\end{abstract}

(c) The Internet Journal of Allied Health Sciences and Practice, 2021 


\section{Role}

5. Establish a two-year early career AH support program to assist entry-level staff manage the size and demands of the job, develop their clinical skills, provide support for professional development and career development, and support social connection in the workplace.

Most entry-level AH participants described experiencing a challenging initial adjustment both professionally (in terms of their confidence level as clinicians and managing the size and demands of the job) and socially (especially newcomers). This challenging initial adjustment to working in rural settings is well established in the literature. ${ }^{7}$ The responses to this recommendation differed between the two services and related to the differing size of their AH workforces. In the RuHS, almost all the AH workforce worked in a single community health team comprising small AH discipline-specific teams (of 2-3 staff) and some solo practitioners. The ReHS staff size was much larger, and most AH disciplines team sizes comprised a minimum of five staff; many were much larger. The ReHS had an AH clinical education coordinator position primarily responsible for the $\mathrm{AH}$ therapies staff as well as an $\mathrm{AH}$ sciences clinical educator. The RuHS had no AH educator on staff.

The RuHS' project worker prioritised this recommendation and over the two-year intervention period developed an Early Career Allied Health Support Program. The program focused on six factors identified in the literature as supporting the job and personal satisfaction of entry-level rural health workers: i) providing orientation, ii) regular discipline-specific clinical supervision, iii) adjustment assistance (one-on-one and group), iv) access to professional development (PD), v) career development advice and support, and vi) social support (see Figure 2). Progress on implementation was supported by some elements already in operation in the service (e.g., i, ii, and iii - group level). Consequently, these program elements only required minor adaptations by the project worker and were already well understood, supported and budgeted for by the executive. With regard to (i) providing orientation, the project worker, using the HR department's generic orientation checklist, worked with $\mathrm{AH}$ managers to re-develop the checklist to address the particular needs of new AH staff. This checklist included matching new staff members with a buddy - as discussed at 9 - and ensuring new staff were provided with a New to Town flyer - discussed at 8 . For (ii) clinical supervision, the executive and $\mathrm{AH}$ managers were already well aware of the difficult adjustment entry-level AH staff faced, especially solo practitioners, and thus the organisation prioritised the arrangement of discipline-specific clinical supervision (provided externally for solo practitioners). ${ }^{6}$ Group level adjustment assistance (iii) to entry-level health $\mathrm{AH}$ staff was provided through regular in-house interprofessional debriefing sessions jointly run with graduate nurses (these debriefings had previously been a standard part of the RuHS' one-year nursing graduate program). The debriefings were run by the RuHS' training and development manager and the project worker. The purpose of the debriefings was to provide entry-level clinical staff opportunities to discuss the demands of their jobs, challenges adjusting to work and moving to town (when relevant), and to strengthen understanding of interprofessional practice and different health professions' scope of practice. Progress on the provision of one-on-one adjustment assistance (iii) required regular contact between the project worker and entry-level AH staff to ensure the support program's strategies were satisfactorily meeting needs. In addition, the project worker was well-placed to provide one-on-one adjustment support, given her understanding of the evidence-base around adjustment issues facing entry-level $\mathrm{AH}$ staff, as well as her previous experience as an entry-level $\mathrm{AH}$ worker in a rural health service and more recently as an $\mathrm{AH}$ manager. At the end of the project, the executive were undecided whether this input would continue beyond the WoP-RIP period. In relation to access to PD (iv), the project worker established a new policy and procedure for AH PD bursaries (discussed below at 6). Activities undertaken by the RuHS to support entry-level AH career development (v) are discussed fully at 7 and social support (vi) is discussed at 8, 9, and 10. The progression of program components entry-level AH career development and social support benefited from their overlapping with WoP-RIF recommendations $7,8,9$ and 10 and are discussed fully below.

In the ReHS, the AH clinical educator and coordinator had already been operating an $\mathrm{AH}$ early career support group for several years before the WoP-RIP started. The group targeted AH staff in their first two years of working and involved planned monthly meetings to address topics identified by participants, which included: making the most of clinical supervision, writing skills for health professionals, communication skills for working in teams, working in a changing environment, and career planning. The program was mostly attended by $\mathrm{AH}$ therapies staff so the focus for the intervention phase of WoP-RIP was to encourage the participation of AH sciences staff. Despite increased promotion of the program, attendance by the AH sciences staff continued to be minimal. The PWG attributed this to their having different workplace cultures, staff mix, and work routines. (This was also considered the reason for lower engagement in social activities by $\mathrm{AH}$ sciences staff, discussed at 9).

(C) The Internet Journal of Allied Health Sciences and Practice, 2021 


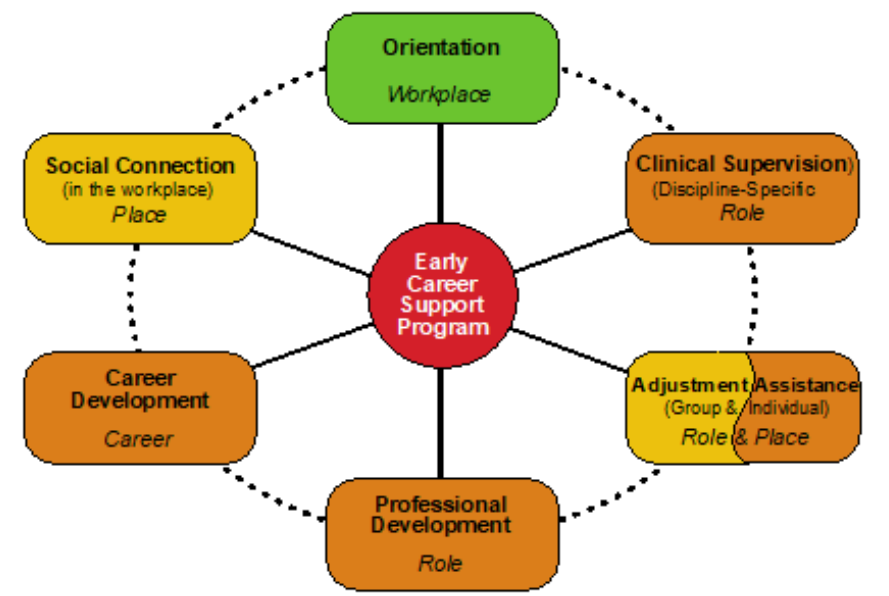

(NB: WoP-RF dom ains are in italics)

Figure 3. The RuHS' Early Career Support Program

6. Review the AH professional development policy and develop a system that is consistent and equitable for all AH staff. In the rural AH health workforce literature, job satisfaction is strongly associated with staff having regular access to PD opportunities. ${ }^{7}$ The level and type of PD support offered to AH staff in both services was found to be neither well understood by staff nor consistently applied by managers. The project worker in the RuHS prioritised this recommendation and in the first six months of implementation drafted a standard operating policy and procedure (P\&P) for PD support for community services staff. The draft P\&P was then reviewed by relevant staff and senior AH management. This review cycle took six months. Related to this P\&P for PD, the project worker garnered executive support for the creation of three annual AH PD bursaries (worth A $\$ 4,000$ each) funded by the health service's foundation. The purpose of the bursaries was to support AH staff to access PD. Applicants were required to demonstrate how the PD would improve their clinical knowledge and skills and identify the immediate benefits to the RuHS. In the ReHS, addressing this recommendation was not planned until Year 2 of the intervention phase of WoP-RIP and, by that time, the executive had decided that PD would be addressed as part of the organisation-wide clinical workforce development plan. The relatively long period (at least 12 months) that the process of developing/reviewing/approving P\&P and resourcing implications was of note for both services.

\section{Career}

7. Build AH managers' understanding of the range of AH career pathways (both clinical and non-clinical) to assist them in better supporting the career development of their staff.

While participants noted that there are few career opportunities available in either service, the AH managers recognised their importance for retaining staff. ${ }^{6}$ The extent of progress on this recommendation differed between the two services. The ReHS did not directly address this recommendation but made some preliminary progress through building AH managers' understanding of the importance of career opportunities for retention by the PWG members making presentations on the WoP-RIF; AH managers' participation in leadership training (these are both discussed above at 4); and development of the ORP (discussed above at 3). Conversely, the RuHS made substantive progress developing and implementing a Career Pathway Tool for use by AH staff to plot their current career position by using a diagram outlining growth rings (gaining experience, further skills and knowledge, and becoming an expert and an acknowledged leader) across different AH work streams (practice, education, research, management, and strategy) adapted from the Victorian Government's Allied Career Pathways Blueprint. ${ }^{16}$ The aim of the RuHS' Career Pathway Tool was to facilitate more strategic and meaningful career conversations between $\mathrm{AH}$ managers and their staff to identify particular interest areas and develop PD plans to support achievement. The tool was formally included in the RuHS' annual performance development review process and involved AH staff completing and submitting before meeting with their line manager. Several training sessions were run by the project worker for $\mathrm{AH}$ managers and staff and both groups gave positive feedback about the tool's potential usefulness in supporting career development. 


\section{Place}

8. Work with community organisations to establish a strategy for professionals relocating to the town/region to feel welcomed and to assist with addressing initial adjustment needs (e.g., housing, local doctor, vet, hairdresser, dentist). Almost all AH participants from both services who had relocated described having similar establishment needs. Initially, these related to finding suitable housing, making friends, and finding recreational activities of interest. ${ }^{6}$ Both services addressed this recommendation by providing new staff with information about the town. The ReHS HR department put together a Welcome Pack that was provided to all new staff during the onboarding stage. It included resources developed by the local council and local businesses, such as information about real estate agents, schools, health and wellbeing services, and recreational groups. More notably, for the whole WoP-RIP period, ReHS HR staff and the PWG were members of a working group established by the local council to assist in the development of a strategy to better attract and support the retention of professionals to the region. The strategy included the development of a council-managed website providing essential information for people interested in moving or having recently relocated to the region, featuring several short YouTube clips from a range of newcomer professionals' relocation experiences. The website launch occurred simultaneously with a national advertising campaign targeting potential professional tree changers. In the RuHS, to assist newcomer staff, the project worker developed a New to Town flyer listing links to the relevant pages on the local council's website and contact details and directions to the local visitor information centre. The flyer was piloted with new staff relocating to the area in the first year of the intervention phase of WoP-RIP and feedback was positive. At the beginning of 2019, the flyer was being routinely distributed by the RuHS HR department as part of onboarding new staff.

\section{Community \\ 9. Ensure there are $\mathrm{AH}$ workforce-wide policies and systems in place to welcome and support the social connection of new AH staff.}

Establishing social connections was a priority issue for most AHPs who had relocated, and work colleagues were commonly relied on for initial social connection. ${ }^{6}$ These workplace social connections also provided newcomer staff with an entrée into the social world of the town, which was described as being difficult to find out about and challenging for some new staff to explore alone. ${ }^{6}$ The responses to this recommendation differed between the two services and this likely related to the differing size of their $\mathrm{AH}$ workforces.

The RuHS responded to this recommendation in two ways: through the establishment of a buddy program and running a regular social event to welcome new staff. The buddy system was developed by the project worker in the first few months of the intervention phase of the WoP-RIP and was initially designed as an inter-professional and inter-team initiative matching new staff with a volunteer staff member of around the same age with shared recreational interests. The program was reviewed after six months and the approach was found to be unfeasible, given staff across teams had differing shifts and competing work demands, making it difficult for matched staff to meet up. The project worker revised the program, and its application was narrowed to the AH workforce only. As a standard part of the orientation process for new community service staff, line managers matched new staff members with an existing team member. The RuHS' social events targeting new health staff were branded Fish Out of Water events. Their aim was to provide an opportunity to meet other newcomers and for the executive to welcome newly arrived staff. The CEO sent invitations to newcomer health staff (including AH, nursing, and medical registrars) and other newcomer health professionals working locally in private practices. The invitation was also extended by the project worker to health students on placement at the time. Three events were held over the two-year intervention period, two in February - a time when many entrylevel health staff commence new positions. Fish Out of Water events were on-site, catered and held straight after work. All three events were well attended by newcomer health staff and members of the executive, including the CEO, who gave a welcome speech at each event. At project end, the RuHS executive committed to holding Fish Out of Water events for newcomer health staff at least once a year.

In the ReHS, the approach taken to supporting the social connection of new AH staff in the workplace was to hold regular morning teas between $\mathrm{AH}$ teams and host semi-regular after work social events. Morning teas were held every two months by AH therapies teams located in the same building/area (as well as other co-located non-AH teams). While the first morning tea was arranged by the project worker, thereafter the AH therapy teams took over the organisation and developed a roster nominating a team to "host." This involved setting up, providing food, and cleaning up. These morning teas were well attended by AH staff (average attendance 41 staff). Despite ongoing efforts by the project worker to encourage the establishment of morning teas within the AH sciences teams (located in different buildings/areas than the therapies teams), little interest was shown. Consequently, no morning teas among this group were held during the project period. The lower levels of involvement in organisation-based social activities by AH sciences staff (compared to AH therapies staff) were related to significant cultural and work routine differences.

The project worker also organised six after work social events for AH staff over the WoP-RIP intervention period. These events were held at licensed venues in the town, with snacks provided and paid for by the ReHS. The average number of attendees was 
23 and the majority (65\%) were $\mathrm{AH}$ therapy staff. While the project worker made several attempts to encourage entry-level $\mathrm{AH}$ staff to form a social committee and take on future planning, these efforts were unsuccessful. The continuation of these organisation-led after-hours social events was thus considered unlikely beyond the project period. A more sustainable, less labourintensive social initiative was the establishment of an AH mixed netball team that played in a local week-day evening competition. The project worker promoted the competition and sought expressions of interest from $\mathrm{AH}$ staff and a full team was formed, with one of the team members agreeing to become the team's convener. Towards the end of the intervention phase of the WoP-RIP, the service-based PWG members established "social activity" as a standing agenda item for all AH team meetings. The aim was to support the continuation of organisation-led social events beyond the life of the WoP-RIP, and to act as a reminder to line managers of the importance for retention, in encouraging the social connection of staff, particularly newcomers.

\section{Work with community organisations to establish a strategy for professionals relocating to the town/region to welcome and encourage social connection and belonging in-place.}

In both services, newcomer staff were generally keen to expand their social connections, especially those who were entry-level, in early adulthood, and unpartnered. The extent of progress made on this recommendation differed markedly between the two services, with the RuHS making little and the ReHS making considerable progress. The key difference between the two was the extent of engagement by the respective local councils. (In Australia, the lowest tier of government is at the local level and is called the council; it is responsible for making local laws and delivering services that reflect community needs.)

In the ReHS, as mentioned at 5, local council established a working group to assist in the development of a strategy to better attract and support the retention of professionals to the region. This involved a community working group with broad community and ReHS staff (including PWG members) representation. As a result of ReHS involvement, a senior representative from the council was invited to join the PRG as a community representative. The working group supported the local council to identify existing groups, services, and recreational activities on offer in the region and the differing recreational interests and social needs of workers across sectors and the life course. The strategy resulted in the development of a website with short YouTube clips of newcomers' experiences, including cameos of ReHS staff and a national advertising campaign aimed at attracting tree changers. These council-developed digital resources promoting the town/region will be used as part of the ReHS' organisation-wide clinical workforce implementation plan as they become available. In the ReHS' final WoP-RIP report, the service-based PWG members described the organisation's ongoing participation in the council's working group as being of 'high strategic importance'. Ongoing participation by the ReHS staff from the HR department is planned to ensure the continued development of resources that can be used to attract and retain clinical staff. Furthermore, in relation to working with community organisations to encourage social connection of new staff, two of the out-of-hours social events organised by the project worker (discussed at 9 above) focused on encouraging broader community connection among newcomers. This involved co-hosted events, firstly with local school principals to encourage the attendance of newcomer schoolteachers, and secondly with the local young professionals' group. These events were one-offs but assessed by the service-based PWG members as having the potential to encourage newcomers' social connection beyond the workplace and an opportunity to meet longer-term residents.

In the RuHS, an after-hours community forum was held at the start of the intervention period, attended by 29 community members and 15 RuHS staff, including the CEO. Its purpose was to promote the WoP-RIP and develop an evidence-informed understanding of the approaches and supports needed to successfully attract, recruit, and retain health professionals to rural towns. Presentations were made by the CEO, the author, and two newcomer staff members who shared their relocation experiences. This was followed by a group exercise for developing strategies to strengthen the social connection of newcomers to the town. The two most popular strategies (by vote) involved establishing community champions to welcome newcomers (and their families) and improving resources for the social and recreational activities on offer in the town/region (the RuHS response to the latter was discussed above at 8). Following on from the forum, a small working group was established to support the project worker in developing a community-based social connection strategy for professional newcomers. It included representatives from local council, the local rotary group and a community member. While some community-based social activities were undertaken in the first six months of the WoP-RIP intervention period, including two events hosted by Rotary to welcome newcomers, overall progress on the town's social connection strategy was minimal. The PWG assessed this failure as arising from local council's waning support for the initiative, resulting in the working group being disbanded and no further activities being planned by the second year.

\section{DISCUSSION}

This study identifies the mechanisms that support (facilitators) or impede (barriers) the successful implementation of localised strategies by rural public health services aimed at strengthening AH workforce under the WoP-RIP domains. The successful implementation of recommendations primarily depended on: i) the role of the health service's HR department, ii) the level of understanding/literacy and commitment from the executive, and iii) the same from AH managers/team leaders. Notably, in the organisational domain, the executive is primarily responsible for the decision-making and HR for the execution of strategies, while 
in the workplace, role and career and community/place (workplace-based) domains, senior AH managers and team leaders lead the decision-making and execution of strategies.

In the two participating health services, the role of HR differed. In the ReHS, the HR director was a member of the executive and consequently HR played a key role in the service's strategic business decision-making. In the RuHS, the HR manager did not sit on the executive and HR primarily played a support function rather a strategic role in decision-making. Consistent with contemporary literature, it was found that the development of an effective clinical workforce strategy was impeded when HR did not play an active role in the organisation's strategic decision-making. ${ }^{19}$

In general, for the effective implementation of all the workplace-based WoP-RIP recommendations, and in particular those in the organisational domain, an organisation-wide change management process with medium-to-long-term commitment of the executive, is needed. To gain this level of executive support, its members need to have an evidence and place-informed understanding/literacy of the factors impacting the attraction, recruitment, and retention of rural health professionals in general and AH in particular. Regular presentations on the WoP-RIF by PWG members to staff, including the executive, assisted in developing this evidence-based understanding/literacy. The presentation to the PRG (which included strong representation by the executive in both services) about the recommendations and their approval to implement, assisted in the development of a place-informed understanding. Effective implementation of organisational recommendations also needed committed and continuous champion(s) in the executive. In the ReHS, this role was performed by the HR director, who led the service's involvement from the outset, negotiated the WoP-RIP funding agreement and was its signatory. In the RuHS, the initial project champions in the executive were the CEO and the community health services director, both of whom resigned from the service within the first six months of the project. From this point, although RuHS executive support for the project continued, no replacement champions emerged and overall enthusiasm for the WoP-RIP waned.

Similarly, the understanding/literacy and support of senior AH managers and team leaders, as well as AH champions was required to support the effective implementation of the WoP-RIP's workplace, role and career and community/place (workplace-based strategies) recommendations. The inclusion of AH managers on the PRG helped build this understanding/iteracy and foster support for the take-up of WoP-RIP strategies at the department/team level. The champion role was in the main held by the servicebased PWG members. With these supportive mechanisms in place, strategies requiring no additional resourcing or changes to P\&P were most easily implemented, even in the ReHS despite it having a much larger and more diverse AH workforce. However, those strategies requiring additional resourcing or P\&P changes generally required the support of the executive and/or HR. Principally as a result of the sustained efforts from the service-based PWG members, this broader level of support was achieved in the ReHS in the last six months of the project, as evidenced by executive's approval of the AH ORP, its commissioning of a clinical workforce implementation plan, and its adoption of the WoP-RIF to support the development and promotion of the plan. In the RuHS, broad level active support from the executive and HR was generally not achieved for the reasons discussed above concerning the role of HR and the lack of an ongoing champion in the executive. Nancarrow et al.'s evaluation of 55 Queensland Health pilot sites involved in AH workforce redesign projects identified two broad principles necessary for effective workforce change that correspond closely to these findings and the WoP-RIP approach: the context needs to be supportive at all levels, including the 'professional environment and leadership and champions'; and mechanisms need to include access to resources to support implementation, a facilitated change management process and suitable governance and support structures. ${ }^{20}$

The participation of local council is essential in the community/place domain (community-based strategies) to support the successful implementation of recommendations involving community engagement. As a local council's role is to undertake work that shapes and builds local community, they are uniquely placed to bring local organisations and individuals together and support them to undertake collaborative work. ${ }^{21}$ Studies demonstrating strong community investment stress the importance of stakeholders having a common vision and sharing the leadership role and planning processes. ${ }^{22}$ The ReHS was able to make significant progress on those WoP-RIP strategies involving community engagement given that the attraction and retention of professionals to the region was also a strategic priority for the local council. This resulted in council forming a working group and inviting large employers to work in partnership to help guide and develop the strategy and resources. In contrast, despite repeated efforts by the executive and PWG, the RuHS was unable to meaningfully engage with its local council; its involvement did not progress beyond informing and consultation. In Arnstein's ladder of citizen participation, this level of participation is defined as "tokenistic" while the partnership approach of the ReHS' local council and its power sharing with local businesses is categorised as "citizen power" - a higher gradation. ${ }^{23}$ The failure of the RuHS to convince local council to participate in the development of social engagement strategies in part relates to local councils in small rural towns having limited resourcing to undertake discretionary community development work. The participation of this local council was further curtailed by the change in CEO during the first year of WoP$\mathrm{RIP}$, which resulted in a general reluctance to commence new initiatives. 


\section{Limitations}

It was not possible to assess the influence of these strategies for improving AH workforce retention, primarily because the WoPRIP was a strategic, high-level intervention requiring rural public sector health services to adopt and commit to organisation-wide cultural change. Assessing the impact of this kind of endeavour requires obtaining the commitment to and investment in longitudinal rural health retention research. While there is a risk of researcher bias in all research, in this project the risk was heightened given the author's multiple and overlapping roles as researcher/collaborator/evaluator. To address this issue, sufficient funding to support a research team rather than a sole researcher and provide external evaluation is required.

\section{CONCLUSIONS}

The implementation of the WoP-RIP recommendations is a complex process requiring whole-of-organisation support by the participating rural public health services. This project identifies five facilitators for successful implementation: 1) the project is considered a strategic HR initiative and overseen by the executive; 2 ) it has strong champion(s) in the executive; 3) HR is part of the strategic decision-making arrangements; 4) the change management process is facilitated and led by staff from the target clinical workforce(s); and 5) a partnership approach with local council is adopted for strategies requiring community support and engagement.

\section{REFERENCES}

1. World Health Organization. Increasing access to health workers in remote and rural areas through improved retention: Global policy recommendations. 2010; Geneva, Switzerland, WHO.

2. Scheil-Adlung X. (2015). Global evidence on inequities in rural health protection: New data on rural deficits in health coverage for 174 countries. ILO Working Papers. International Labour Organization. 2015; Geneva, Switzerland, International Labour Organization.

3. Struber JC. Recruiting and retaining allied health professionals in rural Australia: Why is it so difficult? Internet Journal of Allied Health Sciences and Practice 2014; 2(2): 2.

4. National Rural Health Commissioner. Discussion paper for consultation: Rural allied health quality, access and distribution. Options for Commonwealth Government policy reform and investment. 2019; Canberra, Australian Government.

5. Kumar S; Tian EJ; May E; Crouch R; McCulloch M. You get exposed to a wider range of things and it can be challenging but very exciting at the same time: Enablers of and barriers to transition to rural practice by allied health professionals in Australia. BMC Health Services Research. 2020, 20, 105-114.

6. Cosgrave C. Context Matters: Findings from a Qualitative Study Exploring Service and Place Factors Influencing the Recruitment and Retention of Allied Health Professionals in Rural Australian Public Health Services. International Journal of Environmental Research and Public Health. 2020; 17(16): 5815.

7. Cosgrave C. The Whole-of-Person Retention Improvement Framework: A Guide for Addressing Health Workforce Challenges in the Rural Context. International Journal of Environmental Research and Public Health 2020;17(2698).

8. Onnis LA. Human resource management policy choices, management practices and health workforce sustainability: remote Australian perspectives. Asia Pacific Journal of Human Resources 2019;57(1): 3-23.

9. Malatzky C, Cosgrave C, Gillespie J. The utility of conceptualisations of place and belonging in workforce retention: A proposal for future rural health research. Health Place. 2020;62:102279. doi:10.1016/j.healthplace.2019.102279

10. Abelsen B, Strasser R, Heaney D, et al. Plan, recruit, retain: a framework for local healthcare organizations to achieve a stable remote rural workforce. Hum Resour Health 18, 63 (2020). https://doi.org/10.1186/s12960-020-00502-x

11. Martiniuk A, Colbran R, Ramsden R, et al. Hypothesis: improving literacy about health workforce will improve rural health workforce recruitment, retention, and capability. Hum Resour Health 2019;17, 105. https://doi.org/10.1186/s12960-0190442-9.

12. Minkler M. (2000). Using participatory action research to build healthy communities. Public Health Reports. 2000; 115(2-3).

13. Pawson R. Tilley N. Realistic Evaluation. 1997; London, Sage Publications Limited.

14. Gilmore B, McAuliffe E, Power J, Vallières F.(2019). Data analysis and synthesis within a realist evaluation: toward more transparent methodological approaches. International Journal of Qualitative Methods 2019;18: 1609406919859754

15. Clarke V. Braun V. (2017). Thematic analysis. The Journal of Positive Psychology 2017;12(3): 297-298

16. Charmaz K. Constructing Grounded Theory. 2014. London, United Kingdom, Sage Publications.

17. Miles, M. B. and A. M. Huberman (1994). Qualitative Data Analysis: An Expanded Source Book. Thousand Oakes, California, Sage Publications.

18. Victorian Government. Allied Health Career Pathways Blueprint. 2019. Health and Human Services. Melbourne, Victoria, State of Victoria.

19. Steink C, Dastmalchian A, Baniasadi Y. Exploring aspects of workplace climates in Canada: Implications for the human resources of health-care. Asia Pacific Journal of Human Resources. 2015; 53(4): 415-431. 
20. Nancarrow SA., Roots A, Grace S, Moran AM, Vanniekerk-Lyons K. Implementing large-scale workforce change: learning from 55 pilot sites of allied health workforce redesign in Queensland, Australia. Human Resources for Health. 2013; 11(1): 66.

21. Chaffey H, Bruce S, Woods R. Walking with Communities. Sydney, NSW University of Technology Sydney 2017.

22. Kenny A, Hyett N, Sawtell J, Dickenson-Swift V, Farmer J, O'Meara P. et al. d P. O'Meara. Community participation in rural health: A scoping review. BMC Health Services Research 2013;13(1): 1-8.

23. Arnstein SR. A ladder of citizen participation. Journal of the American Institute of Planners. 1969; 35(4): 216-224. 